\title{
Imagem e percepção humana: alternativa aplicada na classificação da literatura infantojuvenil de uma biblioteca escolar
}

\section{Clériston Ribeiro Ramos}

Bacharel em Biblioteconomia pela Universidade Federal do Rio Grande. MBA em Gestão de Pessoas pela Anhanguera Educacional Rio Grande. Bibliotecário do Sistema de Bibliotecas da Universidade Federal do Rio Grande.

Gisele Vasconcelos Dziekaniak

Bacharel em Biblioteconomia pela Universidade Federal do Rio Grande. Mestre em Engenharia de Produção pela Universidade Federal de Santa Maria .Professora do Instituto de Ciências Humanas e da Informação da Universidade Federal do Rio Grande.

Vanessa Dias Santiago

Bacharel em Biblioteconomia pela Universidade Federal do Rio Grande. MBA em Gestão de Projetos pela Anhanguera Educacional Rio Grande. Bibliotecária do Sistema de Bibliotecas da Universidade Federal do Rio Grande.

Deise Parula Munhoz

Bacharel em Biblioteconomia pela Universidade Federal do Rio Grande. Mestranda do Programa de Pós Graduação em Educação Ambiental.

Esta pesquisa foi baseada no trabalho de Miranda; Poméia; Bueno (2004), o qual defende que fatores culturais e a faixa etária dos alunos são questões que influenciam na percepção humana, e entende que algumas imagens são convencionalmente designadas para diferentes culturas (como a norte-americana e a brasileira). A presente proposta não teve a pretensão de substituir as notações utilizadas para a classificação de assuntos em bibliotecas, amplamente difundidas (notações numéricas da CDD, CDU, etc.), mas sim, sugerir o que esta pesquisa denomina de "rotulação" destes assuntos através de imagens, para que melhor possam representá-los. Acredita-se que o objetivo da 
pesquisa foi alcançado: ordenamento mais claro dos materiais da biblioteca. Sugere-se o desenvolvimento desse sistema de imagens de classificação como forma alternativa de organização de bibliotecas contendo, em seu acervo literatura infantojuvenil.

Palavras-chave: Biblioteca escolar; Organização do conhecimento; Percepção humana.

\section{Human perception and image: alternative implementation classification of the literature of a children's school library}

This research was based on work by Miranda; Poméia; Bueno (2004), which argues that cultural factors and age of the students are issues that influence the human perception, and that some images are conventionally designated for different crops (such as North American and Brazilian). This proposal was not the intention of replacing the notations used for the classification of issues in libraries, widely distributed (numerical ratings of the $C D D, C D U$, etc), but suggest that this research calls "labeling" of these matters through images, that can best represent them. It is believed that the goal of the research was achieved: planning clear materials from the library. It suggests that development of this system of classification of images as an alternative organization of libraries containing its achievements in children's literature.

Keywords: Sschool library; Organization of knowledge; Human perception.

Recebido em06.01.2010 Aceito em 12.12.2011

\section{Introdução}

Dentro do contexto da Ciência da Informação (CI), aqui nos pautamos em Borko (1968) apud Lenzi e Brambila (2006, p. 7, grifo nosso), que a define "como disciplina que investiga as propriedades e o comportamento da informação, as forças que regem o fluxo informacional e os meios de processamento da informação para otimização do acesso e uso". 
Sendo assim, destacamos a biblioteca escolar (BE) como órgão emissor e receptor de processos informacionais. Porém, ainda pouco explorada pela CI. Esta proposta busca enfocar essa interdisciplinaridade.

A incomum abordagem do tema pode ser comprovada no levantamento bibliométrico de Bufrem et al. (2007, p. 44), no qual foram analisados 442 títulos de artigos, distribuídos em revistas científicas da área de CI no Brasil, impressos e eletrônicos, no período de 1970 a 2006. Segundo esse estudo, disposto em ordem crescente de ocorrência de descritores, foi encontrado o seguinte panorama:

Comunicação científica (84 [ocorrências]); Produção científica (81); Análise (48); Bibliometria (47); Publicação científica (42); Ciência da Informação (40); Avaliação científica (35); Informação (29); Literatura científica (24); e Leis da Ciência da Informação (22).

Como percebido pelo levantamento desse estudo, nas revistas científicas da área, até este momento, não se pôde verificar a BE enquanto órgão passível de estudos, no que diz respeito a seu complexo fluxo informacional. Abordagem sugerida pelos próprios parâmetros da CI.

\section{Breve trajetória das bibliotecas escolares}

Para que possamos melhor entender esse tipo específico de organização, Velho et al. (2002/ 2003) nos oferecem um breve histórico das BEs, iniciando-se na precursora Biblioteca Escolar de Aristóteles (por volta de 540 a.C.). Segundo esses autores, essa biblioteca teria "mudado a própria história da humanidade", uma vez que teria auxiliado Demétrio de Farelo e Ptolomeu a fundarem o Museu e a Biblioteca de Alexandria.

Já nos idos de 1004, na "civilização árabe", por iniciativa do califa Al-Hakim, Velho et al. (2002/2003) afirmam que havia pelo menos uma biblioteca em cada cidade, possuindo acesso aberto para estudantes e professores. Na "alta idade média", se estendendo até cerca do Século X, as BEs estavam vinculadas a "mosteiros e conventos", sob a responsabilidade de eruditos, que, também, geralmente se dedicavam à prática do ensino. A partir do século XII, com a criação das universidades, foi marcada uma nova projeção às BEs.

A difusão da imprensa, no Século XVI, possibilitou a multiplicação em grandes escalas do material bibliográfico. Nos Séculos XVII e XVIII, as bibliotecas de Milão, Madrid e Londres entraram em uma nova fase; no Século XIX, as bibliotecas nos Estados Unidos; e Século XX, as bibliotecas na China, destacaram-se.

\section{Papel das bibliotecas escolares na contemporaneidade}

Ainda para Velho et al. (2002/2003), às BEs são atribuídas as seguintes funções: 
- informação - fornecer informação de confiança, rápida e acessível; oferecer orientação na localização, selecção e utilização de informação;

- educação - promover a integração da informação no currículo escolar; facilitar o alargamento compreensivo da inform,ação (sic) recolhida; promover educação contínua;

- cultura - apoio da experiência estética, orientação na apreciação de artes e encorajamento da criatividade; e

- recreio - oferecer um espaço lúdico que permita uma utilização útil do tempo de lazer, através da apresentação de materiais e programas de valor recreativo.

Mas, com as mudanças ocorridas no mundo moderno (amplo senso), às BEs foram conferidas novas atribuições, pois estas se tornaram, também, "um espaço de aprendizagem do uso adequado da informação", pois a utilização da informação de modo preciso é, de fato, uma prática que requer habilidade, treinamento e instrução adequada (VELHO et al., 2002/2003).

A difusão de recursos multimídia, nos mais variados suportes, é outro destaque que revolucionou o aspecto prático do funcionamento das BEs na contemporaneidade.

\section{A escola e a biblioteca escolar}

Quanto à inter-relação entre escola e BE, para Ely (1988) apud Ely (2003/2004, p. 46):

a biblioteca constitui-se em um recurso muito importante de que dispõe a escola para inteirar o processo educacional. Se for bem dirigida, possuir acervos adequados e serviços dinâmicos, deverá ser um lugar atraente que os usuários gostarão de utilizar no seu cotidiano escolar, tornando a biblioteca participante do fazer educativo

Sobre o aspecto ensino-aprendizagem envolvendo a biblioteca escolar, a International Federation of Library Associations (IFLA) ([2000]), por meio do "Manifesto da UNESCO para a biblioteca escolar", afirma que:

A biblioteca escolar (BE) propicia informação e ideias fundamentais para seu funcionamento bem sucedido na atual sociedade, baseada na informação e no conhecimento. A BE habilita os estudantes para a aprendizagem ao longo da vida e desenvolve a imaginação, preparando-os para viver como cidadãos responsáveis.

Contextualizando e relacionando as ideias anteriormente expostas, é possível perceber que a BE possui papel determinante na formação de novos leitores, bem como pode auxiliar na formação de cidadãos críticos.

\section{Habilidades do profissional que atua em BEs}

O profissional que atua em BEs, independente de sua formação é, com efeito, um agente cultural. Sua função se difere dos demais nichos de 
atuação biblioteconômico e a organização do material em BEs não foge desse padrão, pois é preciso adaptar essa organização de acordo com a demanda da comunidade a qual está inserida.

Para tanto, ao contrário do que possa parecer, o "ambiente biblioteca escolar" exige, em tese, um desdobramento do profissional bibliotecário que foge dos conhecimentos tão somente tecnicistas (aplicação de códigos e tabelas de classificação, por exemplo).

Para Ely (2003/2004, p. 46), a organização e funcionamento da BE "devem seguir as modernas técnicas biblioteconômicas", no entanto, alertamos que é preciso cuidado para que não ocorra um distanciamento entre as aplicações desses conhecimentos e o entendimento por parte do usuário, o que poderia se configurar como uma barreira no acesso aos materiais.

\section{Organização das bibliotecas escolares}

A demanda de estudos em organização do conhecimento tem ocorrido em grandes acervos, no entanto, as BEs não são abrangidas. Ainda há muitas questões a serem revistas no que tange à sua organização, pois, como bem sabemos, não existe um padrão a ser seguido em BEs. De um modo geral, seus acervos se diferem muito entre si nos aspectos quantitativos, qualitativos e, sobretudo, quanto ao tipo de público atingido, diferente do que ocorre nas bibliotecas especializadas, por exemplo. O público, em sua maioria, são crianças e pré-adolescentes e, por conta disso, a organização deve proporcionar fácil acesso ao material contido na biblioteca, bem como respeitar e explorar a necessidade pelo lúdico desse público.

A problemática do deslocamento do professor regente de biblioteca, realidade na maioria das bibliotecas escolares brasileiras, é outro fator que justifica o uso de uma simplificação na classificação dos materiais contidos nas bibliotecas escolares. Uma vez que o objetivo é que seus usuários tenham acesso ao material desejado e tenham autonomia à sua localização nas estantes. Neste caso, símbolos da Classificação Decimal de Dewey (CDD) ou Classificação Decimal Universal (CDU), por exemplo, cumpririam papel indesejado. Por outro lado, sabemos que esses sistemas oferecem uma base importante para a classificação de documentos em um acervo físico.

Tendo em vista todo esse contexto, é que decidimos propor uma alternativa de representação do conhecimento por imagens em BEs, utilizando um "rótulo de classificação" para cada assunto, a partir da CDU e de outros materiais auxiliares.

Discutir o aspecto teórico da percepção humana frente à imagem e pautar a discussão de substituição ou uso concomitante de notações de assunto junto a essas imagens, foram alguns dos objetivos que procuramos contemplar na pesquisa. 


\section{Métodos}

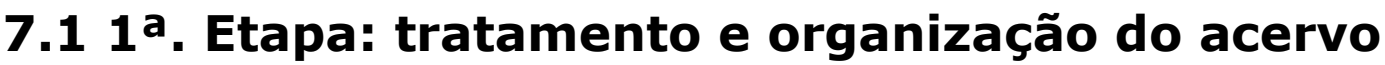

Como etapa inicial, foi realizada revisão de literatura acerca da percepção humana da imagem - com a hipótese inicial de melhor percepção da organização por meio de imagens em detrimento aos códigos tradicionais do campo da organização do conhecimento (CDD, CDU, por exemplo).

O local de realização da pesquisa foi a Biblioteca Rui Barbosa, inserida dentro da escola de Municipal Ensino Fundamental Helena Small, no município de Rio Grande - RS; o tempo de execução foi de agosto a novembro de 2007 - durante o estágio curricular, na disciplina de Prática em Biblioteca.

\subsubsection{Dados da escola e da biblioteca}

A biblioteca contava com 372 sócios, dos cerca de 900 alunos da escola, distribuídos entre os turnos da manhã e tarde; o acervo continha 11.976 registros (as baixas não são descontadas).

\subsubsection{Impressões iniciais da biblioteca}

O material didático estava incorporado ao acervo; a literatura brasileira, parte dela, estava em caixas de papelão, forradas e com recorte da biografia do autor; a literatura estava reunida com os gêneros literários juntos. Como sugestão, foi indicado dividir as literaturas por faixa etária e depois por gênero literário (tentou-se uma divisão por coleção, mas não foi possível, pois misturou-se de novo); os materiais não convencionais (não-livro), não estavam divididos por assunto; os alunos que procuravam tinham dificuldades em encontrar material com assunto específico, como, por duas vezes, foi procurado material sobre lendas; há uma divisão no atendimento da biblioteca: $1^{\text {as }}$. e $2^{\text {as }}$. séries $/ 3^{\text {as }}$. e $4^{\text {as }}$. séries; O empréstimo é de acordo com o turno da escola: quem estuda pela manhã, retira material nesse turno e quem estuda à tarde, retira material somente pela tarde, sendo um dia da semana por turma; havia pelo menos um professor que não costuma devolver os livros; há os relatório para a Secretaria Municipal de Educação e Cultura (SMEC) da cidade, enviados mensalmente, contendo o fluxo de pesquisa dos usuários por assunto; quando o aluno perde algum livro, é exigido outro livro para repor do mesmo tipo (se for gibi, repõe com gibi, por exemplo); haviam divisões dentro das coleções; era preciso restaurar alguns materiais; a responsável pela biblioteca comentou sobre a necessidade de um computador para facilitar o trabalho na biblioteca.

Inicialmente, tentou-se enquadrar as literaturas nas divisões indicadas pela classe 8 (oito) da CDU resumida, a saber: 


\section{Liguagem.Lingüística. Literatura.}

801 Linguística. Filosofia. Línguas.

82 Teoria Literária.

820 Literatura em Língua Inglesa

830 Literatura Alemã/Escandinava/Holandesa

840 Literatura Francesa

850 Literatura Italiana

860 Literatura Espanhola/Portuguesa

869.0(81) Literatura Brasileira

870 Literatura Clássica (Latim e Grego)

880 Literatura Eslava

890 Literatura em outras línguas

82-93 Literatura Infanto-juvenil

82-93 Literatura Infantil

Das subclasses 801 e 890 , foi iniciado processo de divisão nas estantes, com exceção das subclasses 869.0(81) Literatura Brasileira, 8293 Literatura Infantojuvenil e 82-93 Literatura Infantil, no qual foi decidido separar os materiais fisicamente contidos nessas subclasses.

Além da CDU resumida, era utilizada como instrumento de classificação a Tabela de Cutter, para divisão dos autores dentro das subclasses.

Foi notada que a maioria das obras que estavam sendo tratadas tinham pouca utilização, sendo assim, a literatura infantojuvenil foi sendo direcionada, processo esse que tomou tempo considerável, tendo em vista o volume de material.

Nesse segundo momento, foi utilizada outra ferramenta para auxiliar no processo de classificação da literatura infantojuvenil: o Vocabulário controlado para indexação de obras ficcionais (BARBOSA; MEY; SILVEIRA, 2005), tendo como proposta a divisão diferenciada para as literaturas e associando a elas uma imagem representativa do respectivo assunto.

Outra indicação retirada dessa obra foi a substituição das notações geradas a partir da Tabela de Cutter pelas três primeiras letras do último sobrenome do autor, um traço (-) seguida pela primeira letra significativa do título, localizados na etiqueta dos livros, como veremos na FIGURA 1:

Figura 1 - Exemplo de etiqueta da lombada

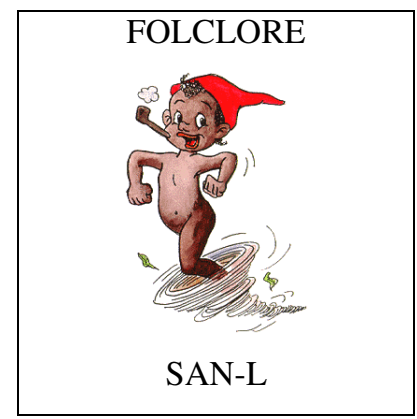

Fonte: Projeto Memória (2007). 
Imagem e percepção humana: alternativa aplicada na classificação da literatura infanto juvenil de uma biblioteca escolar
Clériston Ribeiro Ramos; Gisele Vasconcelos Dziekaniak; Vanessa Dias Santiago; Deise Parula Munhoz

Portanto, valendo-se das indicações, temos o exemplo da obra: Lendas e mitos do Brasil, de Theobaldo Miranda Santos. Retirou-se o SAN, relativo às três primeiras letras do último sobrenome do autor, seguido do traço e a letra $L$, da primeira letra significativa do título. O cabeçalho seria colocado de acordo com o gênero literário, previamente dividido.

Concomitante ao processo de identificação das classes, as imagens foram pré-selecionadas, para que, na pesquisa, pudessem ser eleitas, como veremos a seguir.

\section{$7.22^{a}$. Etapa: pesquisa sobre imagens}

Para seleção das imagens que seriam colocadas nessas lombadas, era preciso entender como funcionava o processo de percepção das imagens, conforme abaixo, com a transcrição do projeto de pesquisa desenvolvido.

\subsubsection{A imagem}

Para Joly (1996, p.13), a imagem é um termo de difícil definição, por conta da multiplicidade de sua aplicação, sendo que, para a autora, esse fator (a aplicação) é que vai determinar sua definição. A origem etimológica da palavra provém do latim imago, que "designa a máscara mortuária usada em funerais na Antiguidade Romana", o que poderia remeter relação à arte envolta naquele ritual. A imagem também pode ser concebida no aspecto mental do funcionamento do cérebro humano; como nos sonhos, no qual são emitidas imagens, similar a um filme (JOLY, 1996, p.20).

Dadas as reflexões, diríamos que imagem, portanto, visa representar um aspecto determinado, passível ou não da interpretação humana, podendo esta ser dinâmica (filmes e outras manifestações) ou estática (pintura em tela, por exemplo).

\subsubsection{Percepção humana da imagem}

Figura 2 - Sistema ótico ocular

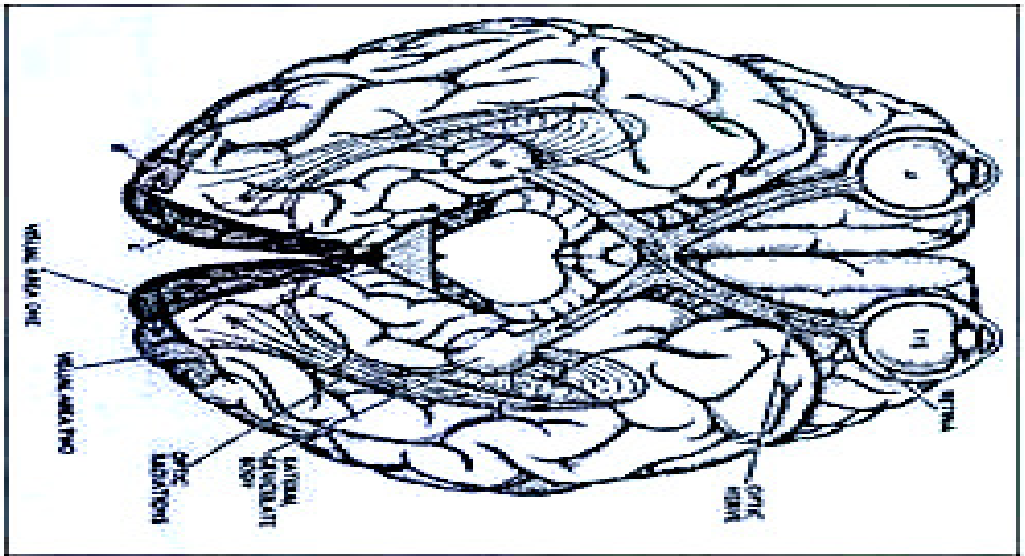

Fonte: Adaptado de interitems ([200-?]). 
O Sistema Óptico Ocular é formado por um complexo esquema fisiológico o qual permite interpretar não somente a sensação de Cor, mas também a profundidade, textura, movimento etc. O qual é formado basicamente pelos globos oculares (olhos), nervos ópticos, corpos geniculares laterais e as áreas de visões. Uma das características deste Sistema é a sua duplicidade, por exemplo, que permite Exibições Estéreodinâmicas possibilitando a insinuação de profundidade esteroscópica constituída pelas diferenças relativas ou disparidades entre as partes das imagens disponíveis nos dois olhos. [...] A parte deste Modelo fisiológico que traduz os raios luminosos em impulsos (sinais químicos) a serem interpretados pelo cérebro são denominados globos oculares (receptores das imagens), os quais são formados pela córnea, íris, retina, etc. A retina, por sua vez, é uma membrana ocular interna, em que estão as células nervosas (bastonetes e cones) que recebem os estímulos luminosos, e onde se projetam as imagens produzidas pelo sistema óptico ocular (INTERITERMS, [200-]).

Tendo em vista essa orientação, é possível afirmar que a interpretação visual demanda do funcionamento de um complexo sistema, onde o globo ocular (Fig. 3) tem a função de receber e assimilar as imagens, e as células nervosas alojadas na retina (Fig. 4), por sua vez, fazem a leitura essa mensagem.

Figura 3 - Globo ocular

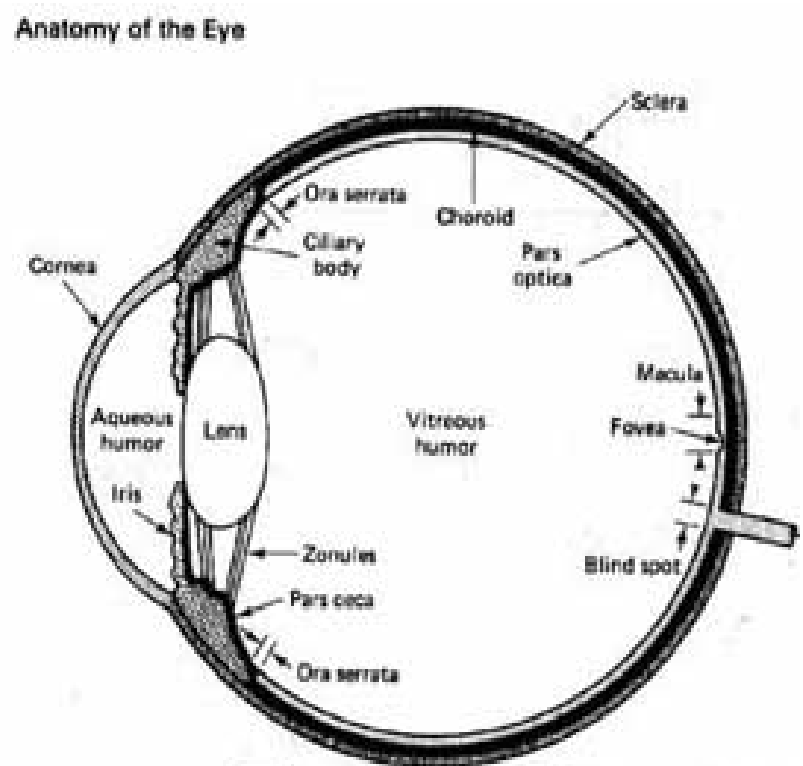

Fonte: Adaptado de INTERITEMS ([200-?]). 
Figura 4 - Células nervosas (bastonetes e cones)

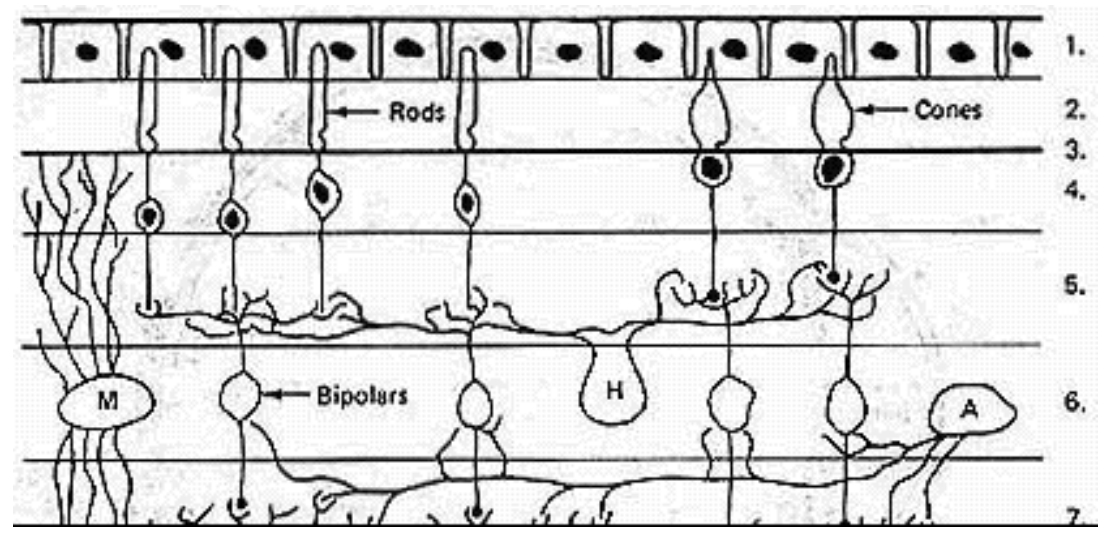

Fonte: Adaptado de interitems ([200-?]).

Foi exposta, até o momento, a estrutura funcional interna da percepção humana da imagem. A percepção visual da figura (aqui tratada como imagem), no ser humano, ocorre em processos sucessivos, como melhor veremos no esquema a seguir.

Figura 5 - Percepção da imagem ${ }^{i}$

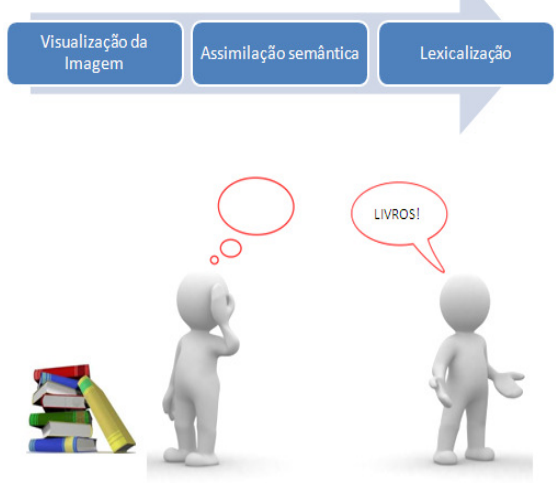

Fonte: Os autores, adaptado de MIRANDA; POMPÉIA; BUENO (2004, p. 226).

Segundo Miranda, Pompéia e Bueno (2004, p. 226), a nomeação da imagem ocorre em três etapas: 1) identificação da imagem, guardando seus aspectos estruturais, para futura recuperação; 2) assimilação semântica, para reconhecimento da imagem; e, finalmente, 3) lexicalização, onde o objeto recuperado é pronunciado.

\subsubsection{Teoria da Gestalt}

Segundo Izidoro (2002), a "Gestalt (forma, todo, configuração)", enquanto corrente da Psicologia, contesta a "explicação das percepções como sendo um conjunto de sensações elementares" e acrescenta, ainda:

O objectivo desta escola foi determinar os princípios que determinam e organizam a nossa percepção, ou seja, o modo como estruturamos a realidade: 
Imagem e percepção humana: alternativa aplicada na classificação da literatura infanto juvenil de uma biblioteca escolar
Clériston Ribeiro Ramos; Gisele Vasconcelos Dziekaniak; Vanessa Dias Santiago; Deise Parula Munhoz

- Um conjunto é mais que a soma das partes que o constituem; e

- A forma é a melhor possível nas condições presentes (princípio da boa forma ou pregnância)

São estes princípios que permitem afirmar que, em condições iguais, os estímulos que formam uma boa figura terão tendência a serem agrupados. (Izidoro, 2002).

Uma interpretação possível seria que a Gestalt aborda a percepção de como uma força humana pode notar as partes e uni-las, percebendo, assim, uma unidade.

Segundo Gomes Filho (2004, p. 19), a percepção visual se divide em "duas forças": externas e internas, sendo as externas "constituídas pela estimulação da retina através da luz proveniente do objeto exterior"; já as internas, "são forças de organização que estruturam uma ordem determinada, dadas de estimulação". Ele acrescenta, ainda, que existem "princípios básicos que regem as forças internas de organização": formação de unidades/contraste, fechamento, boa continuação, proximidade, semelhança, semelhança/proximidade e pregnância.

Nosso foco pretendeu direcionar o estudo no processo humano de percepção da imagem, sendo assim, hipoteticamente, a rotulação das notações de assunto seria um fator que proporcionaria fácil aceitação do sistema. Com isso, em termos práticos, o acervo da biblioteca seria melhor percebido, com identificação imediata pelos usuários e também pelos responsáveis da biblioteca, o que seria obtido por meio do melhor ordenamento do acervo, pautados nos estudos da percepção humana das imagens.

No campo da $\mathrm{CI}$, o aspecto semiológico já foi estudado no processo de indexação, no entanto, não foi encontrado material que relatasse 0 processo que ocorre na percepção humana, dada uma imagem, sendo esse nosso foco teórico de discussão.

A pesquisa proposta baseou-se no trabalho de Miranda, Pompéia e Bueno (2004), na qual, na oportunidade, foi apresentada a crianças brasileiras e americanas, com idades entre 5 e 7 anos, ambos os sexos, objetivando observar "a nomeação, familiaridade do conceito representado e a complexidade visual" contidas em um conjunto de 400 figuras. No entanto, focamos nos resultados deste estudo, no que tange à percepção humana, mais precisamente a reação de crianças em relação às imagens, bem como os fatores que podem influenciar na interpretação delas.

\section{Resultados}

Público: alunos da escola Helena Small, entre as $5^{\text {as }}$. e $8^{\text {as }}$.séries.

Amostra: dois alunos de cada turma (um menino e uma menina), em um total de 32 alunos (a escola possui quatro turmas em cada uma dessas séries). 
Imagem e percepção humana: alternativa aplicada na classificação da literatura infanto juvenil de uma biblioteca escolar

Pré-seleção de três imagens classificação "literatura juvenil":
a) Conto;
b) Novela;
c) Poesia;
d) Romance;
e) Teatro; e
f) Diversos.

Sendo as imagens, a saber:

Figura 6 - Imagens pré-selecionadas
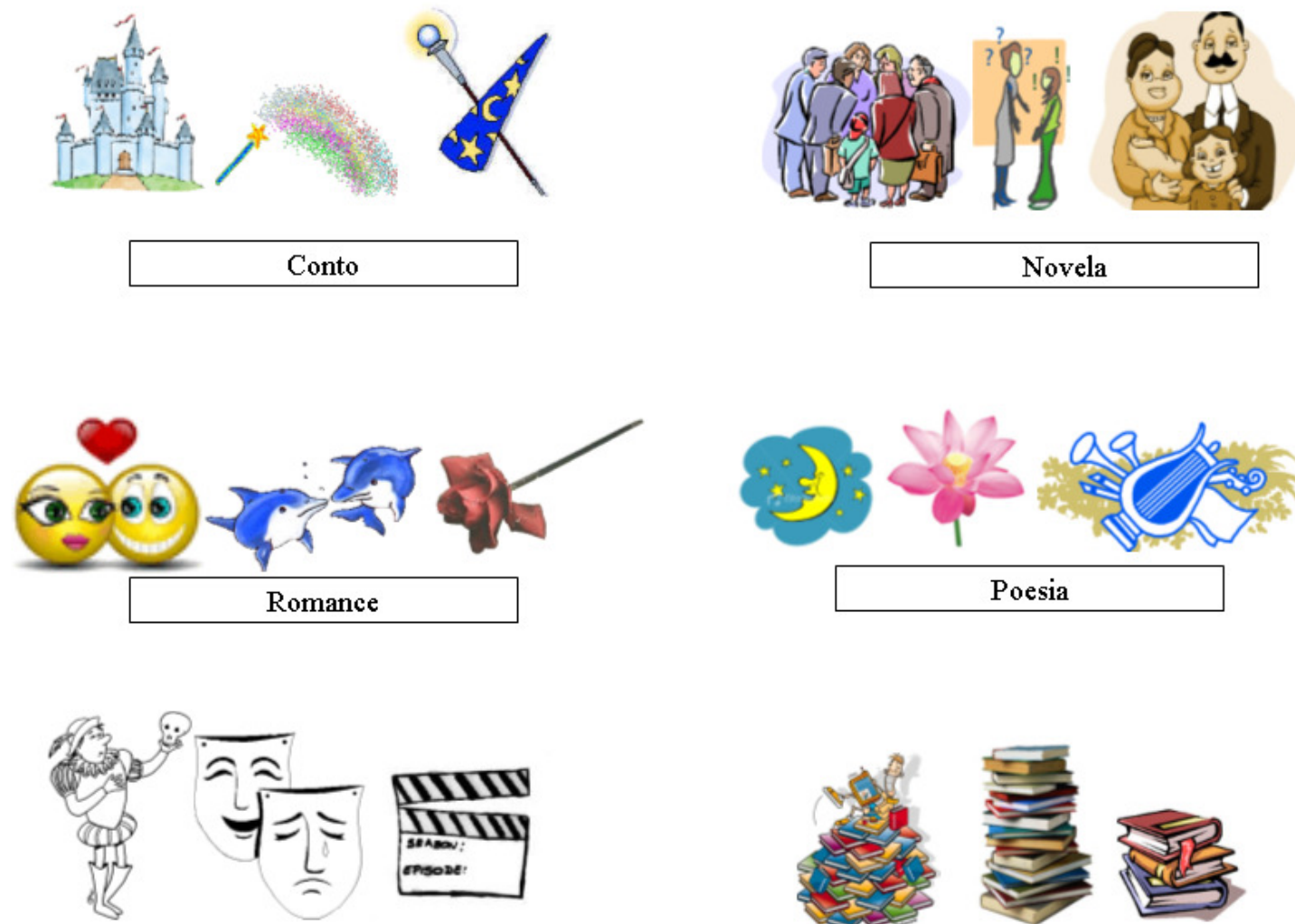

Teatro

Fonte: Os autores, com imagens de uso livre.

Para cada uma dessas imagens, foram confeccionados cartões no tamanho de $16 \times 11 \mathrm{~cm}$, fundo branco.

Um aluno por vez entrava e era explicado que a biblioteca estava pedindo ajuda aos alunos para escolher a imagem que melhor representava cada assunto da biblioteca.

Eram apresentados os cartões de todas as imagens, sem indicação alguma de gênero, e foi pedido que se colocasse nos cartazes da seguinte forma: 
Imagem e percepção humana: alternativa aplicada na classificação da literatura infanto juvenil de uma biblioteca escolar
Clériston Ribeiro Ramos; Gisele Vasconcelos Dziekaniak; Vanessa Dias Santiago; Deise Parula Munhoz

Figura 7 - Método de consulta

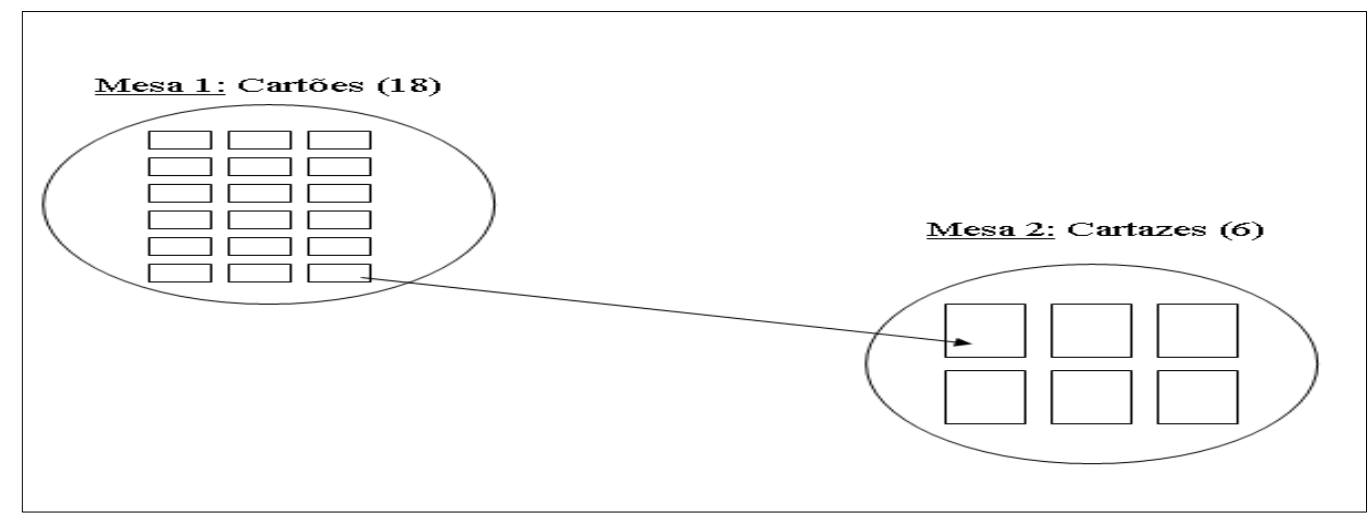

Fonte: Os autores.

Sendo os cartazes, contidos na mesa 2 (Fig. 7), confeccionados em tamanho A4 e apresentados da seguinte forma:

Figura 8 - Cartaz

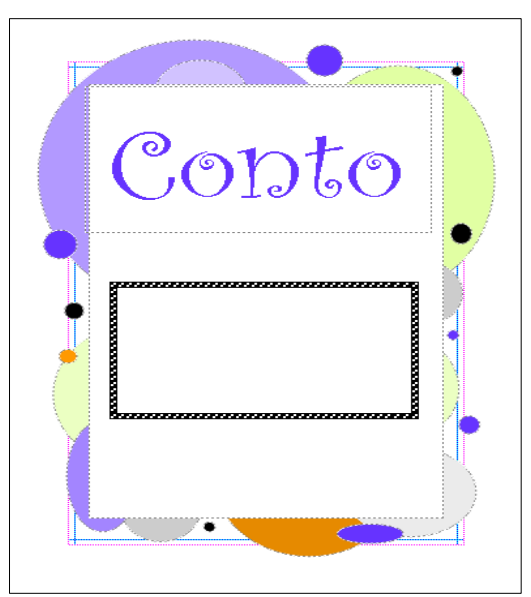

Fonte: Os autores.

\subsection{Resultados das amostras ${ }^{1}$}

Figura 9 - Conto

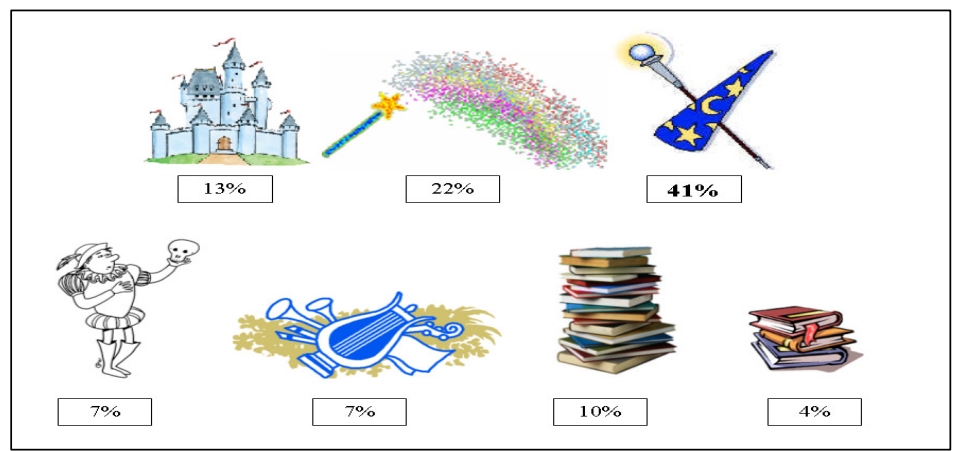

Fonte: Os autores, com imagens de uso livre. 
Imagem e percepção humana: alternativa aplicada na classificação da literatura infanto juvenil de uma biblioteca escolar
Clériston Ribeiro Ramos; Gisele Vasconcelos Dziekaniak; Vanessa Dias Santiago; Deise Parula Munhoz

Figura 10 - Novela

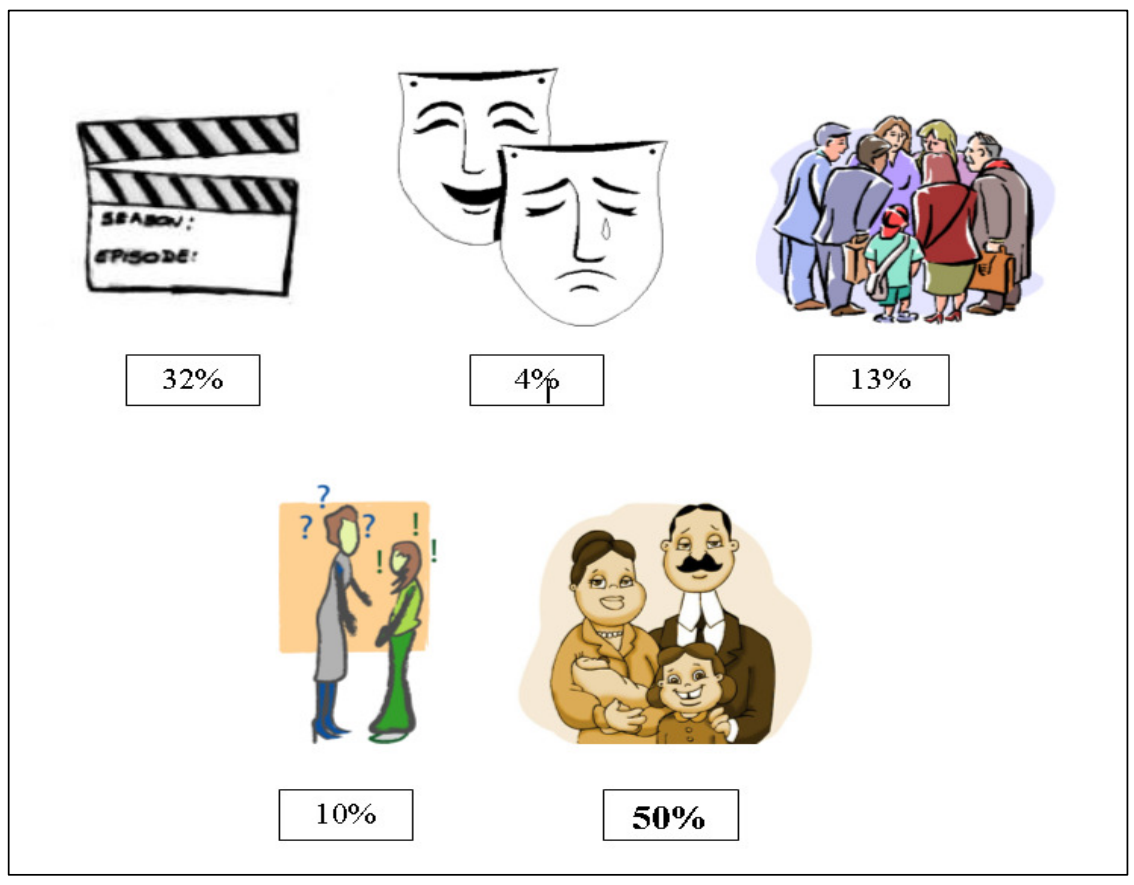

Fonte: Os autores, com imagens de uso livre.

Figura 11 - Poesia

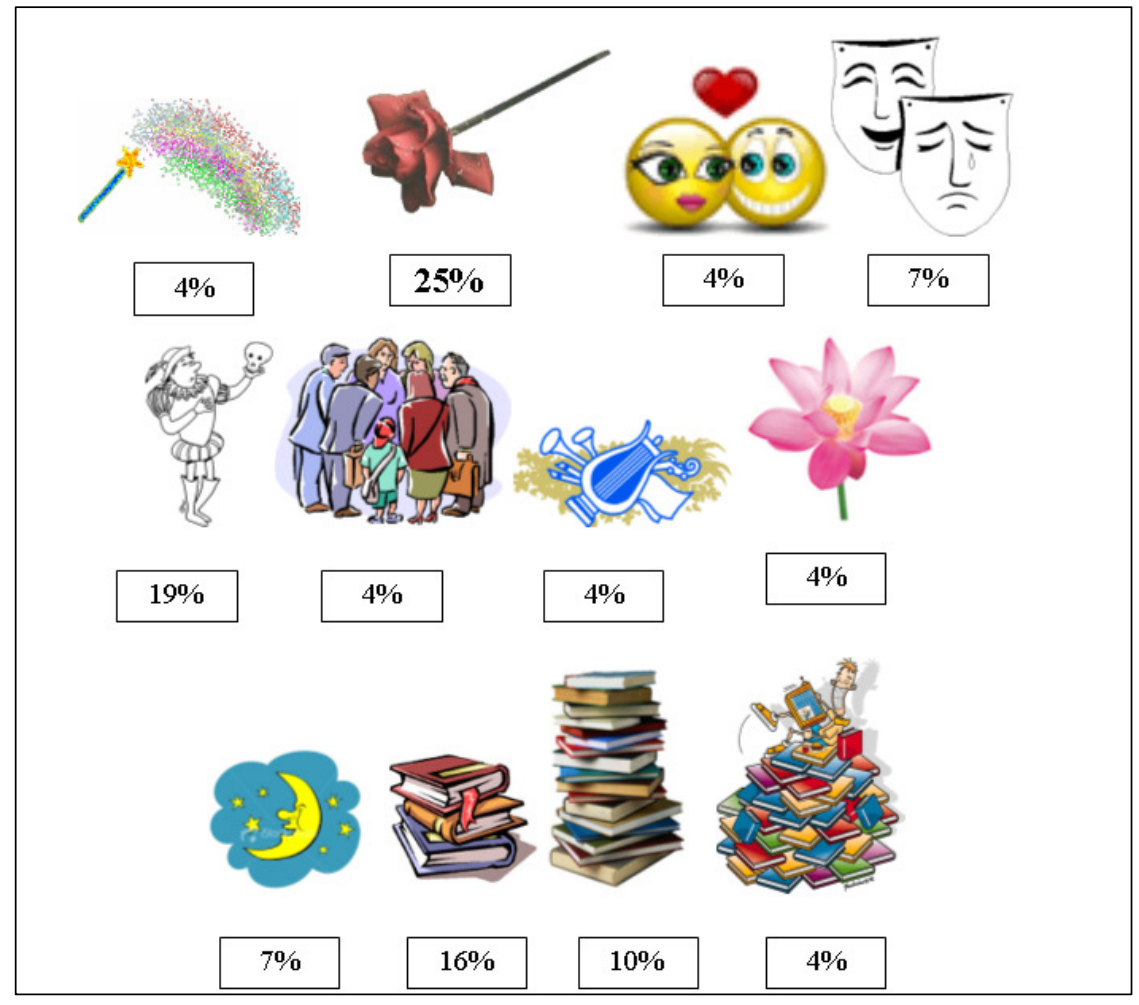

Fonte: Os autores, com imagens de uso livre 
Imagem e percepção humana: alternativa aplicada na classificação da literatura infanto juvenil de uma biblioteca escolar
Clériston Ribeiro Ramos; Gisele Vasconcelos Dziekaniak; Vanessa Dias Santiago; Deise Parula Munhoz

Figura 12 - Romance

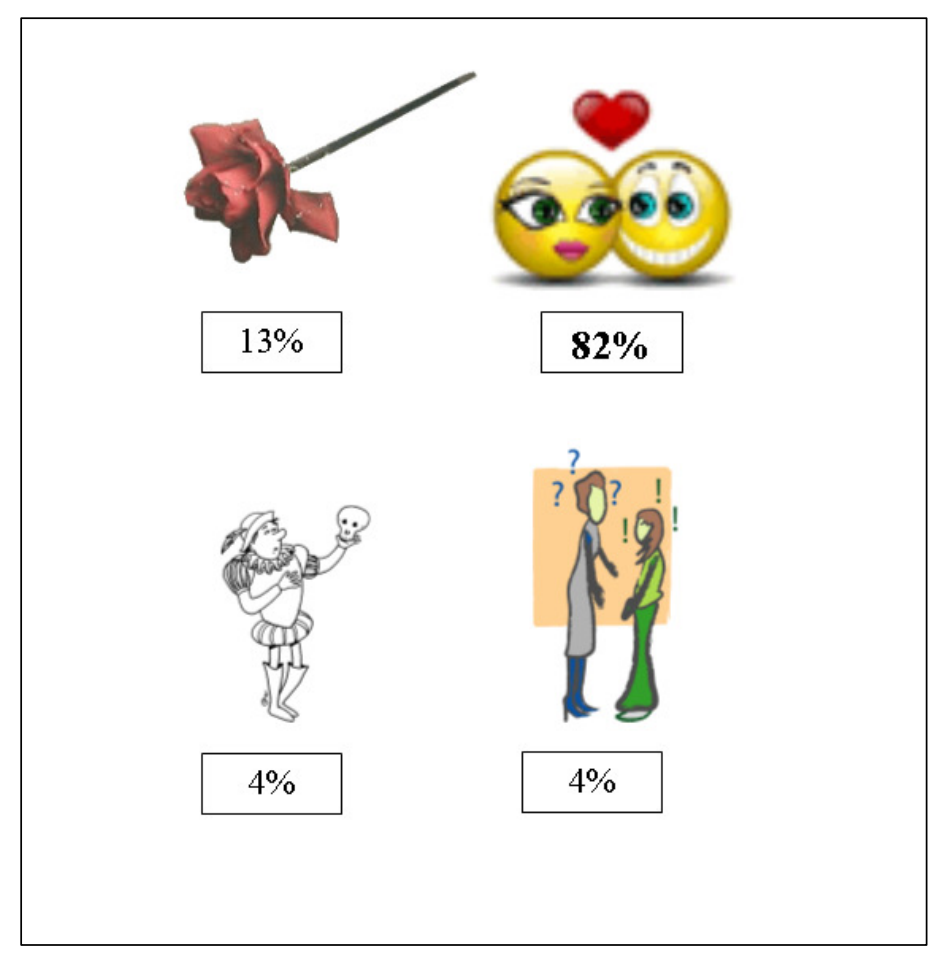

Fonte: Os autores, com imagens de uso livre

Figura 13 - Teatro

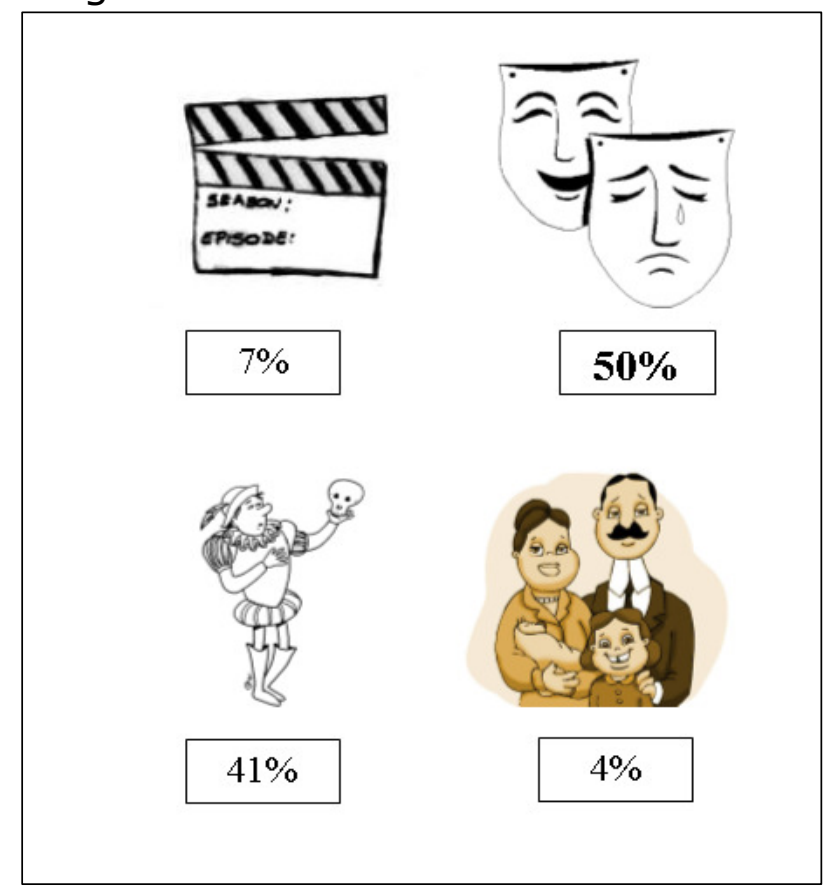

Fonte: Os autores, com imagens de uso livre 
Figura 14 - Diversos

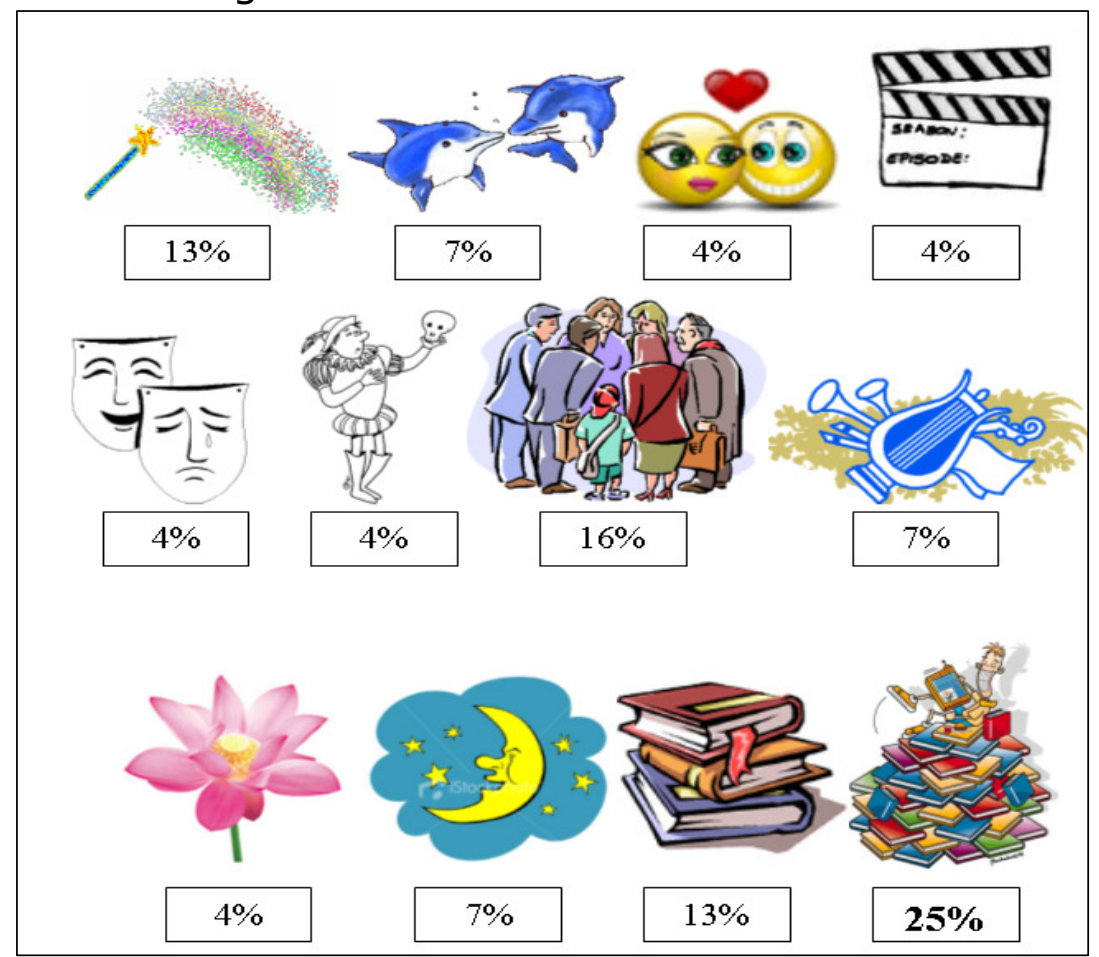

Fonte: Os autores, com imagens de uso livre.

De certa forma, como era esperado - nos contos, novela, romance e teatro - as 3 (três) imagens mais votadas foram as que haviam sido préselecionadas para esses gêneros. Destaque para "novela" e "teatro", que tiveram metade dos votos como imagens mais representativas; e romance, com $83 \%$ das votações para tal gênero.

No entanto, o resultado que mais surpreendeu foi a eleição da imagem de uma rosa vermelha para representar o gênero "poesia", sendo que essa havia sido pré-selecionada para o gênero "romance". O que indica atenção na seleção das imagens para uma possível consulta futura.

\section{Considerações finais}

O sistema de consulta aos alunos se mostrou bastante eficaz, uma vez que na sua aplicação prática, esse público foi tratado como parte do processo de organização da biblioteca, sugerindo uma espécie de "classificação democrática".

Acredita-se que todo esforço no sentido de aproximar as bibliotecas do usuário é válido e, em se tratando de um público especial como o infantil, a "classificação por imagens" se mostrou um método bastante eficaz. Para dar continuidade, foi repassado à responsável da biblioteca Rui Barbosa um CD com as imagens e dos modelos de etiquetas. 


\section{Referências}

BARBOSA, S.; MEY, E. S. A.; SILVEIRA, N. C. Vocabulário controlado para indexação de obras ficcionais. Brasília: Briquet de Lemos, 2005.

BORKO, H. Information Science; what is this? American Documentation, v. 19, n. 1, p. 3-5, 1968 apud LENZI, L. A. F.; BRAMBILA, E. Z. Ciência da informação, ciência e revolução científica: Breve histórico e reflexões. Inf. Inf., Londrina, v. 11, n.1, jan./jun. 2006. Disponível em: $<$ http://www.uel.br/revistas/informacao/include/getdoc.php?id=494\&artic le $=99 \&$ mode $=p d f>$. Acesso em: 25 set. 2007.

BUFREM, L. S. et al. Produção científica em ciência da informação: análise temática em artigos de revistas brasileiras. Perspect. ciênc. Inf., Belo Horizonte, v. 12, n. 1, jan./abr..2007. Disponível em: $<$ http://www.scielo.br/scielo.php?pid=S1413-

99362007000100004\&script $=$ sci arttext\&tIng=pt\#gra2 >. Acesso em: 14 set. 2007.

ELY, N. H. Biblioteca escolar em escolas publicas estaduais 1. grau : um estudo sobre a atualização, adequação e utilização da coleção de livros. 1988. 137f. Dissertação (Mestrado em Educação) - Pontifícia Universidade Católica do RioGrande do Sul, Porto Alegre. 1988 apud ELY, N. H. Dimensões da biblioteca escolar no ensino fundamental. Rev. $A C B$ : Biblioteconomia em Santa Catarina, v. 8/9, p. 46, 2003/2004.

GOMES FILHO, J. Gestalt do objeto: sistema de leitura visual da forma. 7. ed. São Paulo: Escrituras, 2004.

GUILLAUME, P. Psicologia da forma. São Paulo: Nacional, [1966]. 202 p.

INTERNATIONAL FEDERATION OF LIBRARY ASSOCIATIONS (IFLA). Manifesto IFLA/UNESCO para Biblioteca Escolar. [2000]. Disponível em: $<$ http://www.ifla.org/VII/s11/pubs/portuguese-brazil.pdf $>$. Acesso em: 6 de set. 2007.

INTERITEMS. Visão da Linguagem. Percepção visual humana. Disponível em: <http://www.parconsult.com.br/uff/visao.htm>. Acesso em 29 ago. 2007.

IZIDORO, P. Kohler e o Gestaltismo: unidade 1.1.3. 2002. Disponível em <http://www.prof2000.pt/users/isis/psique/unidade1/objecto/kohler.html $>$. Acesso em: 15 ago. 2007.

JOLY, M. Introdução à análise de imagem. Campinas: Papirus, 1996.

LENZI, L. A. F.; BRAMBILA, E. Z. Ciência da informação, ciência e revolução científica: Breve histórico e reflexões. Inf. Inf., Londrina, v. 11, n.1, jan./jun. $2006 . \quad$ Disponível em: $<$ http://www.uel.br/revistas/informacao/include/getdoc.php?id=494\&artic $\underline{\text { le }=99 \& \text { mode }=p d f}>$. Acesso em: 25 set. 2007. 
MIRANDA, M. C. ; POMPÉIA, S. ; BUENO, O. F. A. Um estudo comparativo das normas de um conjunto de 400 figuras entre crianças brasileiras e americanas. Rev. Bras. Psiquiatr., v. 4, n. 26, p.226-233. 2004. Disponível em : <http://www.scielo.br/pdf/rbp/v26n4/a05v26n4.pdf $>$. Acesso em 8 ago. 2007.

PROJETO MEMÓRIA. Sítio do Pica Pau Amarelo. Saci. Disponível em: $<$ http://www.projetomemoria.art.br/MonteiroLobato/sitiodopicapau/image ns/person/saci.gif>. Acesso em: 26 nov. 2007.

VELHO, A. et al. Apontamentos para uma brevíssima história de biblioteca escolar. 2002/2003.

Disponível

em:

$<$ http://www.educ.fc.ul.pt/docentes/opombo/hfe/lugares/nunogoncalves/ apontamentos.htm>. Acesso em 17 set. ago. 2007.

i Estas imagens estão disponíveis nos links a saber: $<$ http://m4bmarketingblog.files.wordpress.com/2009/03/peopletalking1.jpg > e <http://us.123rf.com/400wm/400/400/iserg/iserg0804/iserg080400011/ 2843100-pile-of-books-3d-the-isolated-image.jpg >. 